\title{
Developing 3D Game for Android OS: “SNAFDROID”
}

\author{
Nishant Panwar, Nainesh Vala, Kashyap Rajpal, and Hari Mohan Pandey, Member IACSIT
}

\begin{abstract}
We are developing an ANDROID game "SNAFDROID" with 3-D Graphics that will make the game playing more interesting. The SNAKE game is a well-known and a popular game, giving it a third dimension will make it more intuitive and informative. Giving an option of various environments and train this game can become a legend and will attract various users. Apart from Google Apps developers and vendors are predicted to be the major beneficiaries, since they would make most out of the Android with its wider market structure backed by all the members of OHA, developing different versions of Android, and driving the Android's apps market to a new edge, defeating all the others. Thus, making a SNAKE game (SNAFDROID) with 3D graphics and that too for an upcoming technology like ANDROID will definitely boost the Game playing world of ANDROID OS to a new level of entertainment and fun.
\end{abstract}

Index Terms-Android, 2D graphics, blender etc.

\section{INTRODUCTION}

The term "Android" has its origin in the Greek word andr-, meaning "man or male" and the suffix eides, used to mean "alike or of the species". This together means as much as "being human". Android is a software platform and operating system for mobile devices, based on the Linux operating system and developed by Google and later the Open Handset Alliance [8] [9]. It allows developers to write managed code in a Java-like language that utilizes Google developed Java libraries, but does not support programs developed in native code. Android is just an OS, it requires hardware to run on. Android is hailed as "the first complete, open, and free mobile platform". Android offers a full stack: an operating system, middleware, and key mobile applications [8]. It also contains a rich set of APIs that allows third-party developers to develop great applications. Google released most of the Android code under the Apache License, a free software and open source license.

Android does not differentiate between the phone's core applications and third-party applications. They can all be built to have equal access to a phone's capabilities providing users with a broad spectrum of applications and services. With devices built on the Android Platform, users are able to fully tailor the phone to their interests. Android breaks down the barriers to building new and innovative applications. Android provides access to a wide range of useful libraries and tools that can be used to build rich applications. In addition, Android includes a full set of tools that have been

Manuscript received June 12, 2012; revised August 31, 2012.

Hari Mohan Pandey is with faculty Department of Computing of the Middle East College, Muscat, Oman (e-mail:hari04top@yahoo.co.in)

Nishant Panwar, Nainesh Vala, and Kashyap Rajpal are with Accenture India (e-mail-nishant_panwar23@yahoo.com; naineshvala@gmail.com; kashyaprajpal@yahoo.co.in) built from the ground up alongside the platform providing developers with high productivity and deep insight into their applications.

This first worldwide mobile network was introduced by the USA in 1946 and could only be used nationally at that time, mostly for military purposes. Not until the end of the 1950's was this technique replaced by the Analog network (A-network). Then in 1973, Motorola presented a prototype of the world first cellular telephone. It was about one foot long, weight almost 2 pounds and cost $\$ 3995$. This cell phone which became commercially available in 1983 provided one hour of talk time and could store 30 phone numbers. In only one year 300, 00 people, worldwide, were owners, considering price, this was remarkable market growth.

TABLE I: HISTORY OF ANDROID

\begin{tabular}{|l|l|}
\hline Year & Description \\
\hline 2005 & $\begin{array}{l}\text { Google acquired Android, Inc., a small company that developed } \\
\text { software for mobile phones. "Android, Inc." team started } \\
\text { working on a Linux-based OS for mobile devices. }\end{array}$ \\
\hline 2006 & $\begin{array}{l}\text { Media and press was filled with news about Google entering the } \\
\text { mobile market }\end{array}$ \\
\hline 2007 & $\begin{array}{l}\text { November 2007, the Open Handset Alliance \& mobile operators } \\
\text { started working together to develop handsets and services that } \\
\text { leverage the new software. }\end{array}$ \\
\hline 2009 & $\begin{array}{l}\text { Sing Tel \& HTC Corp. unveiled the first Android powered } \\
\text { mobile phone - The HTC Dream. }\end{array}$ \\
\hline
\end{tabular}

In the nutshell changes of the hardware related mostly to improvement in weight, price and look. The operating system was improved by e.g. games, calendar applications, email and other functionalities to use the internet. This development underlines clearly what a cell phone needs today. It must be as small as possible, it has to be "stylish" and it has to cover a wide range of functions especially internet connection which is used by many people in the world every day. Android has emerged as one such operating system [9] which provide most of such demanded features.

\section{II.ARCHITECTURE AND FEATURES}

The Android platform is designed to be more fault-tolerant than many of its predecessors. The handset runs a Linux operating system, upon which Android applications are executed in a secure fashion. Each Android application runs in its own virtual machine. Android applications are managed code; therefore, they are much less likely to cause the phone to crash, leading to fewer instances of device corruption.

Blender is a free 3D graphics application that can be used for modeling, UV unwrapping, texturing, rigging, water and smoke simulations, skinning, animating, rendering, particle and other simulations, non-linear editing, compositing, and creating interactive 3D applications, including video games, animated film, or visual effects [1][2]. Blender's features include advanced simulation tools such as rigid, realistic 
body, fluid, cloth and soft body dynamics, modifier-based modeling tools, powerful character animation tools, a node-based material and compositing system and Python for embedded scripting [3]. Released as free software under the GNU General Public License, Blender is available for a number of operating systems, including GNU/Linux [9], Mac OS X, and Microsoft Windows [3] [4].

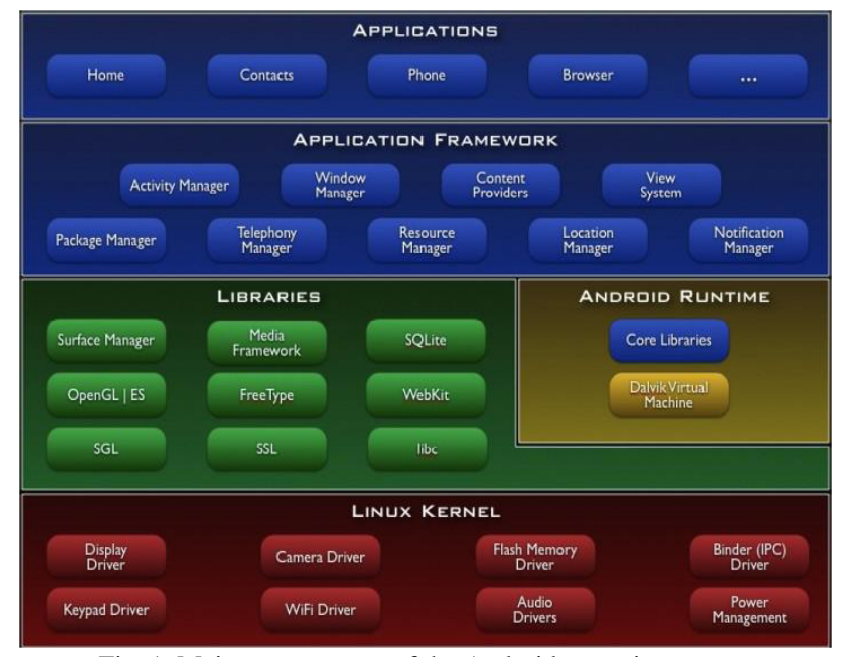

Fig. 1. Major components of the Android operating system

Through its open architecture, Blender provides cross-platform interoperability, extensibility, an incredibly small footprint, and a tightly integrated workflow [10]. Blender is one of the most popular Open Source 3D graphics applications in the world. Aimed world-wide at media professionals and artists, Blender can be used to create 3D visualizations, stills as well as broadcast and cinema quality videos, while the incorporation of a real-time $3 \mathrm{D}$ engine allows for the creation of $3 \mathrm{D}$ interactive content for stand-alone playback. Originally developed by the company « Not a Number » $(\mathrm{NaN})$, Blender continues to be developed as "Free Software", with the source code available under the GNU GPL license. Development is now conducted under the leadership of the Blender Foundation in the Netherlands.

Blender has a relatively small installation size and runs on several popular computing platforms, including LINUX, Mac OS X, and Microsoft Windows, along with FreeBSD, IRIX, NetBSD, OpenBSD and Solaris [1][2][3]. Among its capabilities are:

a) Support for a variety of geometric primitives, including polygon meshes, fast subdivision surface modeling, Bezier curves, NURBS surfaces, metaballs, digital sculpting, and outline fonts.

b) Versatile internal rendering capabilities and integration with YafaRay, a Free Software ray tracer.

c) Key framed animation tools including inverse kinematics, armature (skeletal), hook, curve and lattice-based deformations, shape keys (morphing), non-linear animation, constraints, vertex weighting, soft body dynamics including mesh collision detection, LBM fluid dynamics, Bullet rigid body dynamics, particle-based hair, and a particle system with collision detection.

d) Modifiers to apply non-destructive effects.

e) Python scripts for tool creation and prototyping, game logic, importing and exporting from other formats such as
OBJ, FBX, DXF, COLLADA, task automation and custom tools.

f) Basic non-linear video/audio editing and compositing capabilities.

\section{PROBLEM DEFINITION}

In this paper authors have given the idea of develop a 3D game for Android OS. The game which is being developed covers the following things:

- Provide an interactive and intuitive environment for ANDROID users who are passionate about playing games.

- We are here to develop a 3D game for Android OS.

- 3D Game proposed is SNAKE GAME: "SNAFDROID”

- The mobile screen will be 2D but the graphics used are $3 \mathrm{D}$ providing a more informative and interesting environment

-

\section{PEREVIOUS WORKS}

In 1982 the Finnish handset maker Nokia introduced its first Mobile phone, "Mobira Senator". This device looked very much like a portable radio and weight 21 pounds. The first cell phone with PDA features was introduced in 1993 by Bell South/IBM. It included phone and pager functionalities, calculator and calendar applications as well as fax and e-mail capability. The weight was about 18 pounds and it sold for \$900. Motorola’s “StarTac”, in 1996, merged fashion and functionality. Its weight was about 3.1 pound's which is lighter than some of today's cell phones. Kyocera introduces its QCP6035 mobile phone in year 2000. It was the first widely available Palm OS based phone.

In 2002 the Danger Hip top, later known as the T-Mobile Sidekick, was introduced. It was one of the first mobile devices to include a Web browser, reliable e-mail access and instant messaging. With the RAZRv3 Motorola again came back and started a trend towards ultra-thin, stylish phones. It was the first mobile device which many people from high scholars to businessmen wanted to have, primarily, because of its style and because it was fashionably. It is still one of the most popular mobile phones today. The last very impressing innovation was presented by Apple with the release of the iPhone in 2007, a beautifully designed cell phone that includes an innovative touch screen navigation interface.

\section{V.APPROACH USED}

In this section we are presenting the track of implementing the system for the 3D game for Android.

\section{A. Algorithm Used and Implemented}

\section{Algorithm 1: Implementation of SNAFDROID}

S1 Loading of game and checking of availability of resources.

S2 Loading of game engine.

S3 Display the menu.

S4 If selected option equals START GAME

S5 Then display "Menu for selection of environment"

S6 If selected option is OPTIONS 
S7 Then display "Menu for changing controls/sounds etc".

S8 If selected option is Exit

S9 Exit the game and free resources.

After the initial loading of game and resources the game engine is loaded. The game engine starts with a startup screen which displays the logo and a moving snake. A menu is displayed afterwards. The menu has various options like START Game etc. If start game option is selected then a menu is displayed which consists of option regarding selection of terrain in which the user wants to play. The commencement of game takes place henceforth. Selecting EXIT button free all resources and exit the game.

\section{B. Use-Case Diagram}

Figure 2 shows the use case diagram of our game. This diagram consists of actor, use cases and interface. There is one actor i.e. user. The ellipses represent use cases and lines shows relationship between actor and use cases.

\section{Sequence Diagram}

Figure 3 shows the sequence diagram for the present work. Sequence diagram is a kind of interaction diagram. It shows an interaction, consisting of a set of object or roles, including the messages that may be dispatched among them. It addresses the dynamic view of a system. It emphasizes the time ordering of messages.

\section{D.Class Diagram}

A class diagram shows a set of classes, interfaces and collaboration and their relationships. Figure 3 represents class diagram. It consists of 5 packages, 8 classes and 3 interfaces. Here ScakeGameActivity is the main class that simulates and triggers various operations.

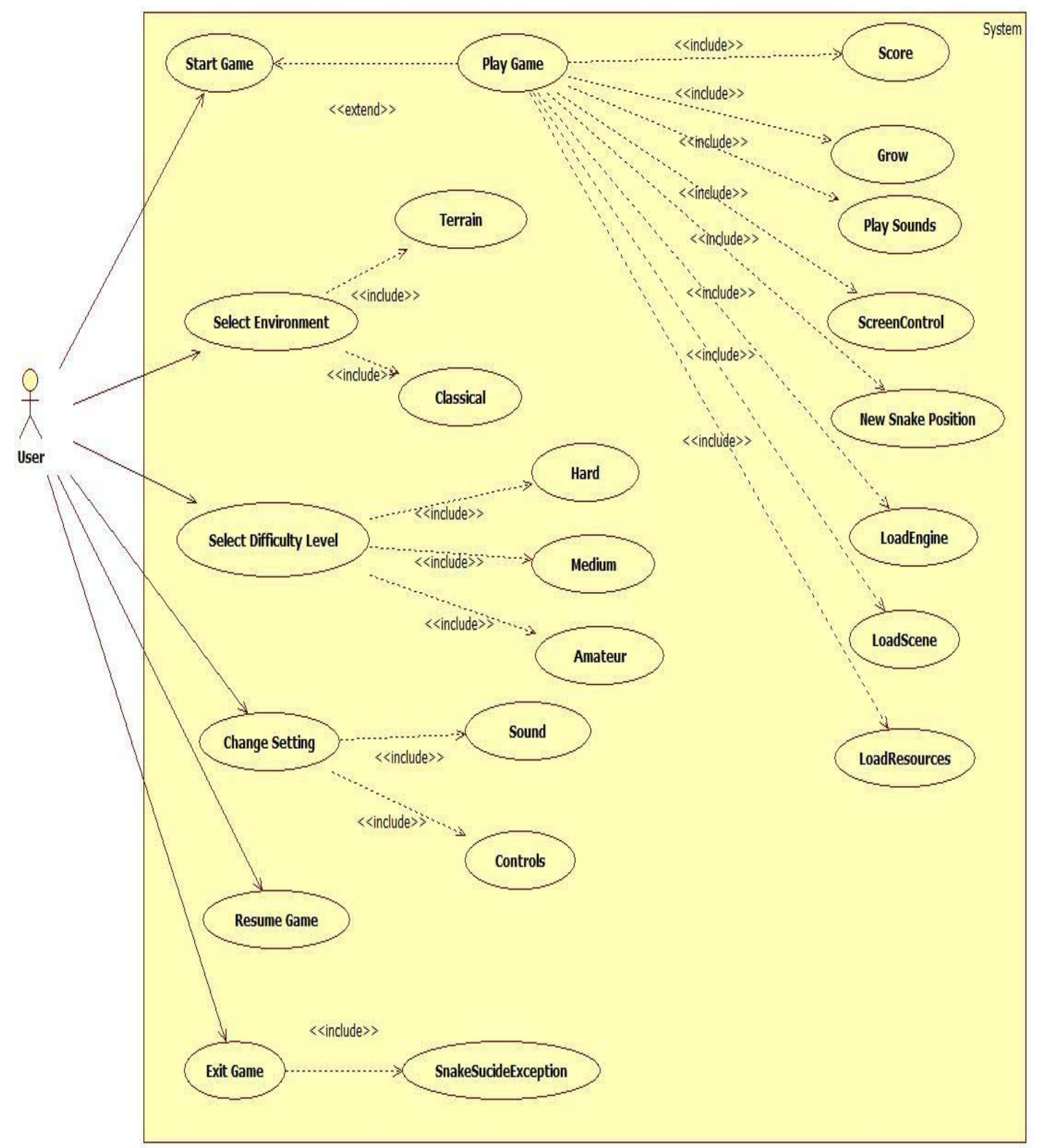

Fig. 2. Use-case diagram 


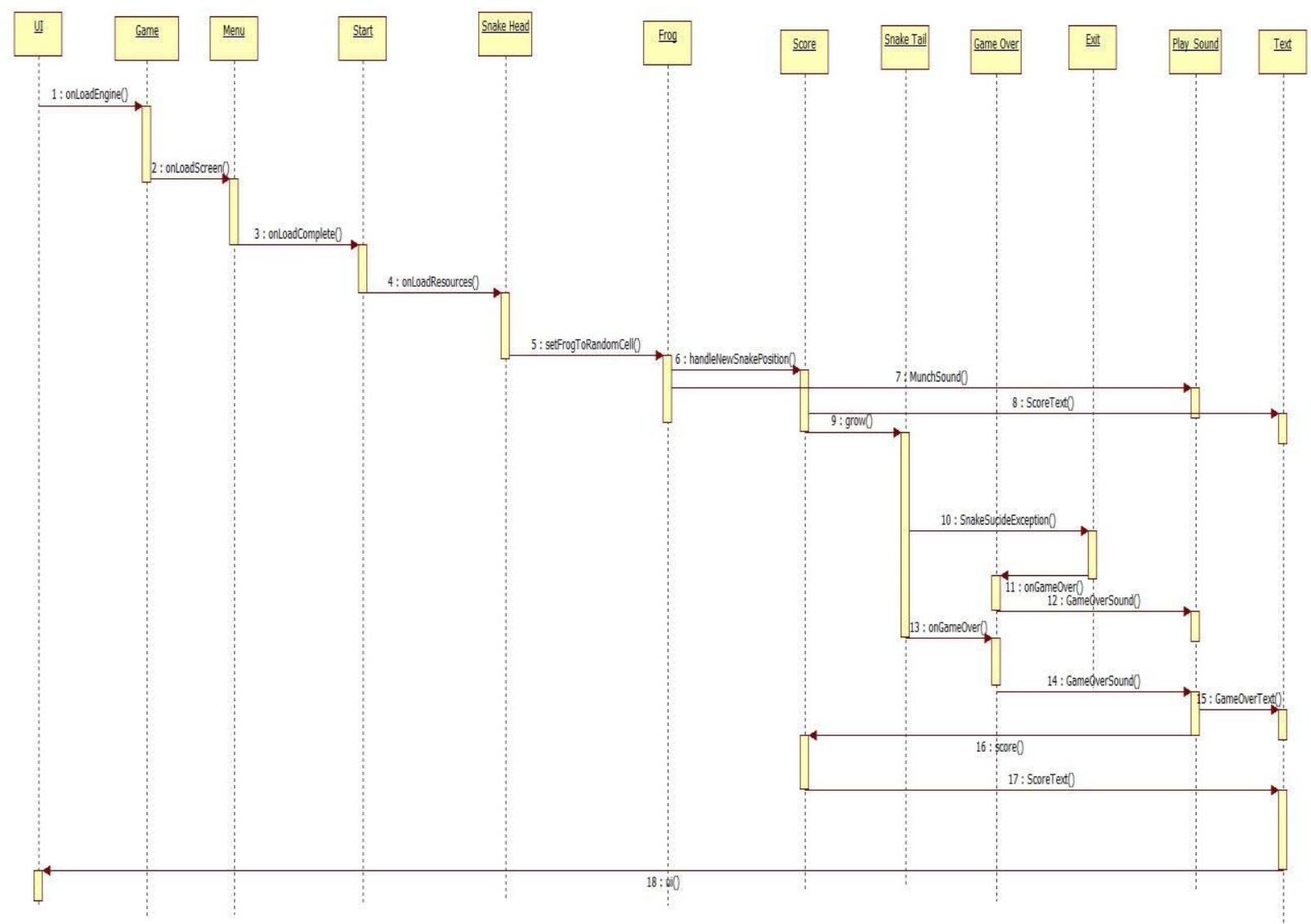

Fig.3. Sequence diagram

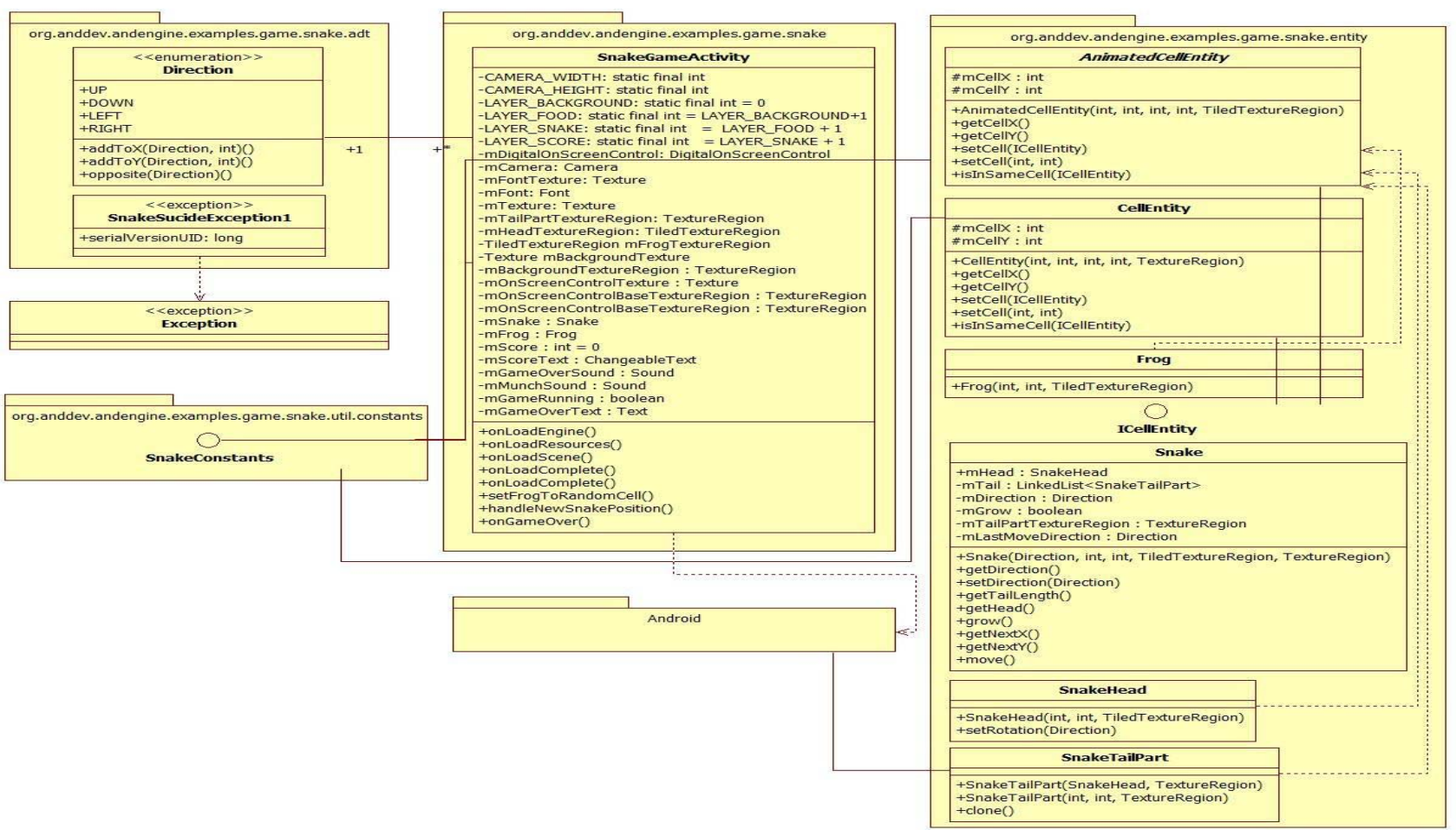

Fig. 4. Class diagram for SNAFDROID

\section{EXPERIMENTAL SETUP}

To be used efficiently, all computer software needs certain hardware components or other software resources to be present on a computer. These pre-requisites are known as system requirements and are often used as a guideline as opposed to an absolute rule. Most software defines two sets of system requirements: minimum and recommended. With increasing demand for higher processing power and resources in newer version of software, system requirements tend to increase over time. Industry analysts suggest that this trend plays a bigger part in driving upgrades to existing computer systems than technological advancements. The chief hardware and software requirement for the present 
work is shown in the Table II.

TABLE II: HARDWARE AND SOFTWARE REQUIREMENTS

\begin{tabular}{|c|c|}
\hline Category & Tools \\
\hline \multirow{4}{*}{ Hardware } & $\begin{array}{l}\text { 1. Hardware requirements of the system on which } \\
\text { application is developed }\end{array}$ \\
\hline & $\begin{array}{l}\text { a) Min } 4 \text { GB RAM } \\
\text { b) Min } 1 \text { GB space on HDD } \\
\text { c) Graphics Card } \\
\text { d) Min } 512 \mathrm{MB} \\
\text { e) NVIDIA/ATI } \\
\text { f) } \text { Processor Core } 2 \text { Duo with } 2.2 \mathrm{GHz}\end{array}$ \\
\hline & $\begin{array}{l}\text { 2. Hardware Requirements of the system on which } \\
\text { application is intended to run }\end{array}$ \\
\hline & a) Mobile phone compatible with Android OS \\
\hline \multirow{4}{*}{ Software } & 1. Software required on which application is developed. \\
\hline & $\begin{array}{l}\text { a) Android SDK (Ver. } 2.2 \text { and above, API Level } 8 \text { and above) } \\
\text { b) Java } 1.5 \text { and above } \\
\text { c) OS: Windows (XP/Vista/7) } \\
\text { d) Eclipse IDE } \\
\text { e) BLENDER-graphic design tool }\end{array}$ \\
\hline & 2. Software on which application is intended to run \\
\hline & a) Android OS \\
\hline
\end{tabular}

\section{A. Results}

In this paper authors have given an Android game "SNAFDROID", consists of two modules: Graphics Development module and Coding.

As far as this project is concerned we have completed the software requirement and specification and we are developing graphics for our 3D game. These graphics require high system specifications. We are using blender, a graphics development tool using which we have developed various graphics that will be used in our game. The graphics require exhaustive rendering power of the rendering engine being used by the graphics development tool. Some of the screenshots of the graphics developed for the present project are shown in the figures 5, 6, 7, 8 below:

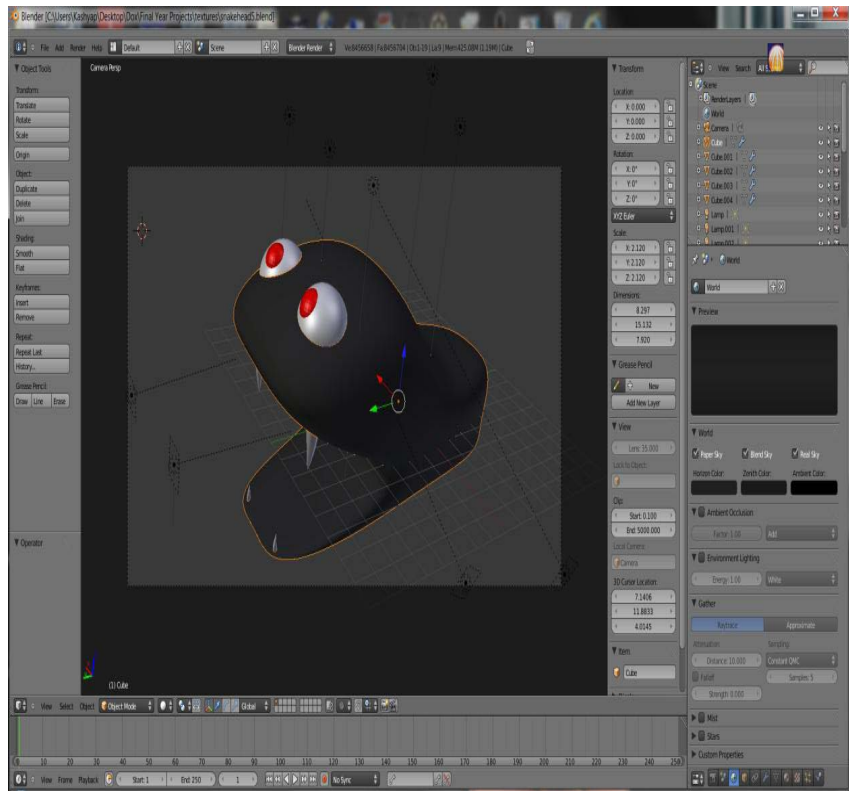

Fig. 5. Snake head development in blender

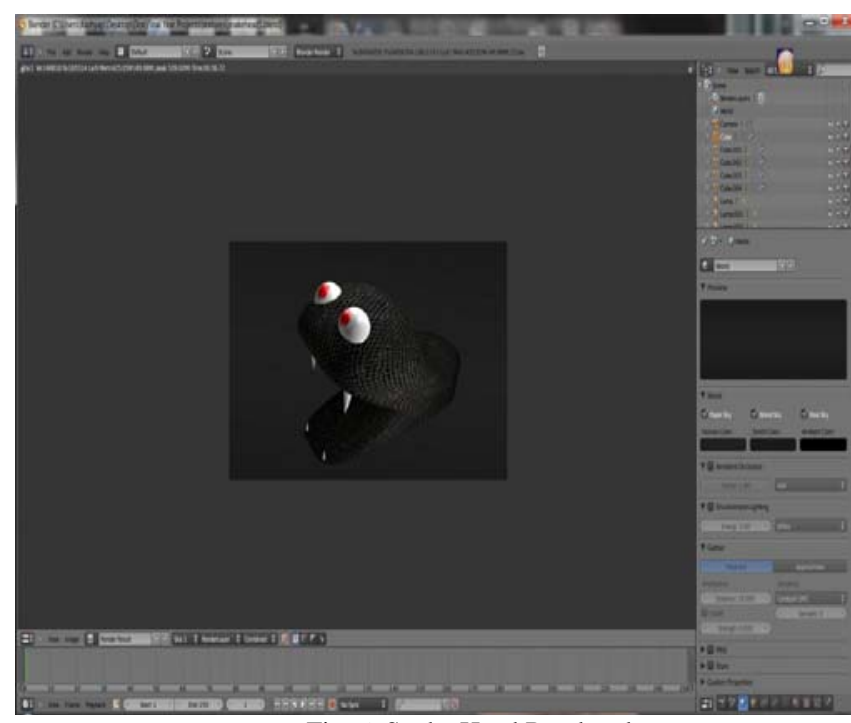

Fig. 6. Snake Head Rendered

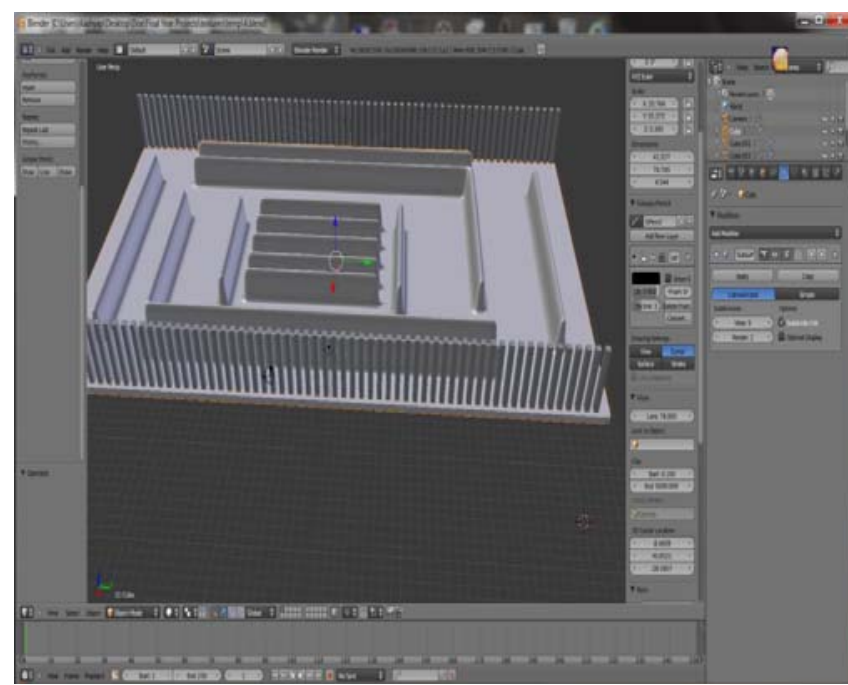

Fig. 7. Maze environment

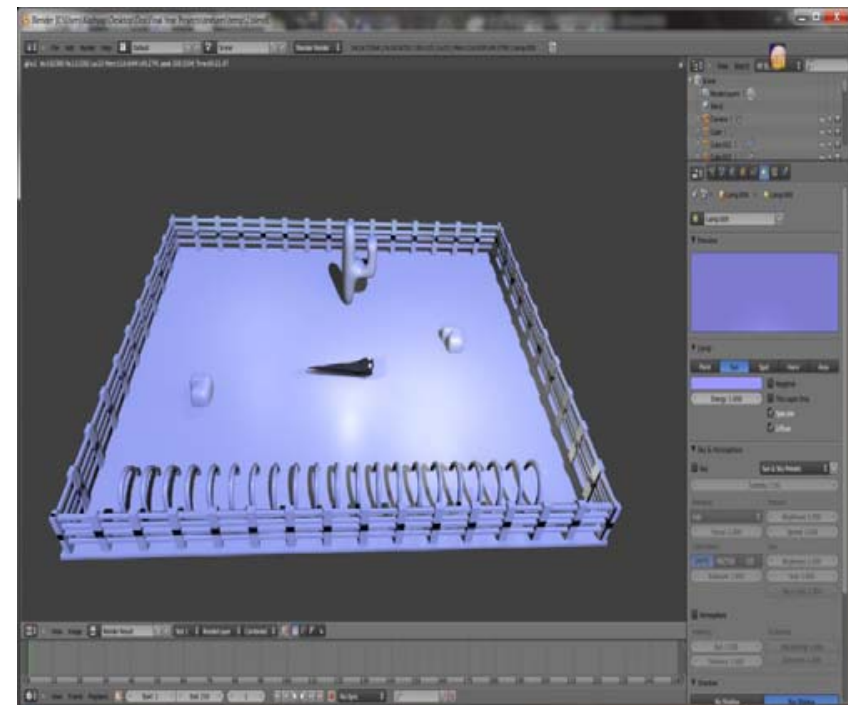

Fig. 8. Snow desert environment

\section{CONCLUSION AND FUTURE ENHANCEMENT}

Android has come a long way since its inception three years ago. It will surely impact the mobile market when the Android phones are released, but also provides an excellent opportunity for developers to enter the mobile market. A 
great deal can be learned by both creating applications using Android's unique Java API as well as attempting to port Android to real hardware [10]. The classroom cans befit from Android, given the amount of resources available for reference.

The market trends toward the mobile market and future developments can be greatly benefited by using Android to improve their algorithms and resource management. Since it is open source, there is no cost to learn. Android is a win-win situation for both the community and developers. Android will be bigger in terms of pure numbers (reach) than the iPhone OS.

\section{REFERENCES}

[1] D. Roland Hess, Animating with Blender: Creating Short Animations from Start to Finish 1st Ed. Focal Press, September 30, 2008.

[2] Jason Van Gumster, Blender for Dummies, $2^{\text {nd }}$ ed. Wiley Publishing, Inc. 2009

[3] James Chronister, Blender Basics $2^{\text {nd }}$ Ed. January 24, 2008

[4] Aaron W. Powell, Blender 2.5 Lighting and Rendering, Packet Publishing, Ingles, 252 paginas, Nov. 2010, ISBN: 1847199887.

[5] Tony Mullen, Introducing Character Animation with Blender, Sybex, Inglés, 512 páginas, Feb. 2007, ISBN: 0470102608

[6] Open Handset Alliance, [Online]. Available: http://www.openhandsetalliance.com/

[7] ANDEV, [Online]. Available: http://www.andev.org

[8] Android, [Online]. Available: http://www.android.com

[9] ELINUX, [Online]. Available: http://elinux.org/Android_on_OMAP

[10] Open Embedded, [Online]. Available: http://wiki.openembedded.net/index.php

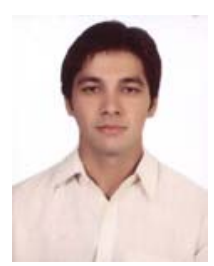

Nishant Panwar was born in Dehradun, Uttarakhand, India on December 23, 1988. He completed his schooling from Dehradun in 2007. In 2011 he received his B.Tech. degree in computer science from Mukesh Patel School of Technology Management and Engineering (Shirpur Campus), NMIMS University, Mumbai, Maharashtra, India.

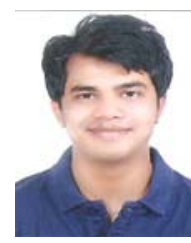

Nainesh Vala was born in Bhavnagar, Gujarat, India on December 19, 1989. He completed his schooling from Mumbai in 2007. In 2011 he received his B. Tech. degree in computer science from Mukesh Patel School of Technology Management and Engineering (Shirpur Campus), NMIMS University, Mumbai, Maharashtra, India.

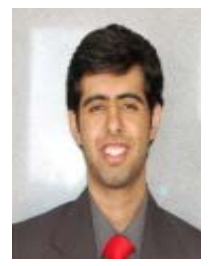

Kashyap Rajpal born in city of lakes, Udaipur (Raj.), India on April 1, 1990 completed his higher education from Central Academy School, Udaipur. In 2011 he received his B.Tech. degree in computer science from Mukesh Patel School of Technology Management and Engineering (Shirpur Campus), NMIMS University, Mumbai, Maharashtra, India. Kashyap's major field of study is development of various JAVA applications and new trends in mobile industry.

He is currently working as an Associate Software Engineer (ASE) at Accenture Services Pvt. Ltd., Bangalore, India. He presented various papers and articles on topics like Aspect Oriented Programming (AOP) and Image processing. His previous researches include Aspect Oriented Programming, Image Processing, Robotics and his current researches include agile methodology and payments in banking industry.

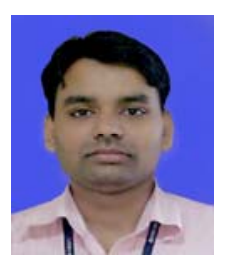

Prof. Hari Mohan Pandey B.Tech. (Computer Science \& Engineering), M.Tech (Computer Engineering) was educated at U.P. Technical University, Lucknow and Narsee Monjee Institute of Management Studies, Mumbai, India. Presently he is working as a faculty in department of Computing at Middle East College of Information Technology.

$\mathrm{He}$ is life time member of International Journal

IJERIA (India), International Association of Computer Science Information Technology (Singapore), International Association of Engineers (IAENG, Hong Cong), and reviewer for Elsevier.

Prof. Pandey has written many books in the areas of Computer Science \& Engineering for McGrawHill, Pearson Education, and University Science Press. Apart from writing books he has presented and published Research Papers at National and International conferences and journals. He is associated with various International Journals as Reviewer/Editorial board member. His research interests are in Artificial Intelligence, Machine Learning, Evolutionary Computing, Natural Language Processing, Principle of Programming Languages and others. 